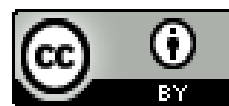

Esta obra está sob o direito de Licença Creative Commons Atribuição 4.0 Internacional.

\title{
O PROCESSO DE ALFABETIZAÇÃO E LETRAMENTO
}

Andréa Santos Pereira ${ }^{45}$

\section{RESUMO}

O presente trabalho aborda a temática dos processos de alfabetização e letramento, tendo como objetivo entender os conceitos e processos de alfabetização e letramento na perspectiva da prática docente, pois, são processos distintos, complexos e interdependentes, que devem estar presentes na sala de aula, portanto, é um processo de contínua reflexão sobre o ato de leitura e escrita, considerando que esta possui várias funções e deve expressar idéias, pensamentos e intenções dos alunos, através de experiências sociais significativas. Todavia, a necessidade de um embasamento teórico foi que estimulou a pesquisa cientifica, para construção deste artigo. De acordo com o que foi pesquisado, pretende ainda promover a compreensão do letramento como perspectiva de sucesso na aprendizagem da leitura e da escrita frente às novas exigências sócio-educacionais. Contudo, a alfabetização é um pressuposto indispensável para o letramento, pois o aprendizado da leitura e da escrita permite ao sujeito a compreensão de diferentes informações veiculadas.

Palavras chave: Aluno. Docente. Alfabetização. Letramento.

\footnotetext{
45 pereiraandrea576@gmail.com.br

*Aluna Pós-graduada em Docência do Infantil e Fundamental, pela Faculdade Atlântico, em e graduada em Pedagogia, pela Universidade Estadual Vale do Acaraú- UVA.
} 


\section{1- INTRODUÇÃO}

Ao abordar o tema processo de alfabetização e letramento, o presente artigo foca em algumas situações sobre questões que fundamentam a prática da alfabetização e do letramento na atualidade considerando que a prática do professor precisa ser avaliada e renovada constantemente, porém, foi necessário fazer um estudo sobre o assunto discutido, com comentários de grandes autores especialistas.

As dificuldades de apropriação do letramento no contexto educacional atual é um desafio a ser transposto através da mediação pedagógica, o que remete à consideração de dois aspectos importantes desta análise. $\mathrm{O}$ primeiro refere-se à concepção de letramento que fundamenta esse artigo e que servirá de eixo norteador para a indicação de possíveis sugestões para a apropriação eficaz da leitura e da escrita no contexto da sala de aula.

Pode-se perceber, portanto, que o processo de letramento poderá ser mais eficaz se basear-se no estudo de textos diversificados relacionados aos elementos sócio-culturais da realidade do aluno e que lhe possibilitem a ampliação dos recursos comunicativos de que já dispõe.

Esses recursos são, numa análise mais simplificada, a oralidade e os saberes sociolinguísticos que a criança adquiriu em suas práticas letradas e que já detém ao chegar à escola, conhecimentos que servirão de base para sua aprendizagem e a partir dos quais serão construídos novos conhecimentos.

O segundo aspecto é abordado pela a ação do docente, que hoje se mantém mais aberto a novas idéias e estratégias, ou seja, há uma tendência por parte dos professores em melhorar sua prática através da reflexão sobre a própria ação com o objetivo de superar suas deficiências e desenvolver aspectos positivos, tanto no que se refere à interação professor-aluno, como na qualidade do processo de aprendizagem.

Contudo, acredita-se que a leitura e produção de textos na escola devem ter como objetivo o letramento, isto é, tornar o aluno usuário da leitura e escrita em todos os aspectos, como instrumento de comunicação com o mundo.

Sendo que, a exploração de diversificados textos, é uma possível prática pedagógica que atende aos objetivos que oportunizam o desenvolvimento da expressividade, do uso funcional da linguagem, da leitura e reflexão holística, construindo um leitor que lê com compreensão e escreve, expressando pensamentos, comunicando idéias, interagindo com seus semelhantes.

O objetivo deste artigo é entender melhor $\mathrm{o}$ processo de alfabetização $\mathrm{e}$ letramento, portanto, acredita-se que de acordo com o que foi trabalhado o objetivo foi alcançado.

\section{2 - ALFABETIZAÇÃO E LETRAMENTO SÃO PROCESSOS DIFERENTES, MAS COMPLEMENTARES}

O conceito de alfabetização, por muito tempo, ficou atrelado à idéia de que para aprender a ler era necessário apenas á capacidade de decodificar os sinais gráficos, transformando-os em sons, e que para aprender a escrever era necessário apenas desenvolver a capacidade de codificar os sons da fala, transformando-os em sinais gráficos.

A partir da década de 1980, várias teorias mostram que o aprendizado não se reduziria ao domínio de correspondência entre grafemas e fonemas, mas se caracterizaria como um processo ativo, por 
meio do qual, desde os primeiros contatos com a escrita, a criança construiria e reconstruiria hipóteses sobre a natureza e o funcionamento da língua escrita como um sistema de representação. Segundo Cagliari,

O processo de alfabetização inclui muitos fatores e, quanto mais ciente estiver o professor de como se dá o processo de aquisição de conhecimento, de como uma criança se situa em termos de desenvolvimento emocional, de como vem evoluindo o seu processo de interação social, da natureza da realidade lingüística envolvida no momento em que está acontecendo a alfabetização, mais condições terá esse professor de encaminhar de forma agradável e produtiva $\mathrm{o}$ processo de aprendizagem, sem os sofrimentos habituais. (CAGLIARI, 1999).

O conceito de letramento entra em cena e amplia a visão de alfabetização, chamando a atenção não apenas para o domínio da prática de ler e escrever (codificar e decodificar), mas também para o uso dessas habilidades em práticas sociais em que ler e escrever é necessário. Magda Soares (1998) define letramento como:

Letramento é o resultado da ação de ensinar e aprender as práticas sociais de leitura e escrita; é o estado ou condição que adquire um grupo social ou indivíduo como consequiência de ter-se apropriado da escrita e de suas práticas sociais (SOARES, 1998).

Alfabetização e letramento são processos diferentes, cada um com suas especificidades. Porém, ambos são indispensáveis quando se leva em consideração a aprendizagem da leitura e da escrita.

Ainda segundo Soares (1998), a entrada da criança no mundo da escrita, ocorre simultaneamente por esses dois processos:" a alfabetização desenvolveseno contexto de e por meio da aprendizagem das relações fonemas/grafemas, isto é, em dependência da alfabetização". Indispensáveis para se garantir a inserção e a participação efetiva nas sociedades letradas, a alfabetização e o letramento são processos diferentes, mas complementares e inseparáveis.

Reconhecendo a especificidade de cada um desses processos, é preciso combinar a alfabetização e o letramento, assegurando aos alunos tanto a apropriação do sistema da escrita, como o domínio das práticas sociais de leitura e escrita.

Como consequiência, o desafio que se coloca é "alfabetizar letrado", ou seja, possibilitar que a alfabetização se desenvolva em um ambiente onde a criança conviva com variados portadores de textos ao mesmo tempo em que constrói a base alfabética.

O professor, mediador nessa prática de alfabetização, não pode ser visto apenas como sendo um aplicador de pacotes educacionais ou um mero constatador do que o aluno faz ou deixa de fazer. Ser mediador desse processo significa estar entre os conhecimentos e o aprendiz e estabelecer um canal de comunicação entre esses dois pilares.

\section{1 - COMO A CRIANÇA APRENDE}

$\mathrm{O}$ primeiro e mais importante aspecto a ser considerado no processo de alfabetização é aquele relacionado ao seu caráter conceitual. Isso significa que o aluno irá construir ele mesmo como sujeito ativo e pensante o seu conhecimento como leitura e escrita.

A construção desse conhecimento não é fácil, nem tão pouco simples. Trata-se 
de uma aprendizagem complexa, individual e subjetiva, mas não solitária, porque exige ao mesmo tempo troca de informações, estimulo e motivação.

$\mathrm{O}$ aluno precisa criar e recriar o sistema gráfico, com normas próprias de utilização e com sinais que representem a sua escrita, antes de apropria-se do sistema convencional.

As crianças vivem em ambientes ricos em experiências de leitura e escrita, não só se motivam para ler e escrever, mas começam, desde cedo, a refletir, ter sobre as características dos diferentes textos que circulam ao seu redor, sobre seus estilos, usos e finalidades (PCN- Língua Portuguesa, 2007, p.70).

Essa apropriação do conceito da leitura e da escrita obriga o aluno a formular hipóteses e a enfrentar contradições e diferenças entre sua construção pessoal e a escrita alfabética que encontra em seu ambiente escolar e comunitário.

Para que a exploração e experimentação aconteçam de forma positiva, torna-se necessário passar pelos "erros" próprios do processo de construção do conhecimento. Esses erros construtivos, que são as formas de ler e escrever criadas pelas próprias crianças, quando confrontadas com as experiências convencionais, dará origem aos conflitos cognitivos que funcionam como motor da aprendizagem, isso se a criança for tratada pelo professor como capaz de pensar e fazer as atividades de leitura e escrita.

Quanto às dificuldades enfrentadas pela criança nesse processo, se, anteriormente, eram consideradas erros que era preciso corrigir, e para isso os recursos eram, de novo, os exercícios ou "treinos" de imitação, repetição, associação, cópia; hoje, no quadro de uma nova concepção do processo de aquisição do sistema de escrita os erros são considerados construtivos. (SOARES, 1999, p. 53).

Desafiada e livre para experimentar, a criança reformula suas idéias e procura respostas mais seguras e cada vez mais próximas do conceito alfabético da escrita. Mas, para isso, ela precisa errar, ou seja, precisa de um tempo para escrever de acordo com sua forma de pensar.

É preciso encorajar a criança a
descobrir e inventar, sem ensinar
ou dar conceitos prontos. A
resposta pronta só deve ser dada
quando a pergunta da criança
focaliza um ato social arbitrário
(funções do objeto cotidiano).
Manter-se atento à série de
descobertas que as crianças vão
fazendo, dando-lhes o máximo de
possibilidades para isso. Dar
atenção a cada uma delas,
encorajando-as a construir e a se
conhecer. Dar maior incentivo à
pergunta que à resposta. Sempre
buscando no grupo a resposta o
professor procurará sistematizar e
coordenar as ideias emergentes. A
relação que se estabelece com o
grupo como um todo a pessoal
com cada criança é diferenciada
em todos os seus aspectos
quantitativos e cognitivos
respeitando-se a maturidade de seu
pensamento e a individualidade.
(SALTINI, 1997, p.90).

Ao inventar o seu sistema de escrita, o aluno não deve perder de vista a função comunicativa do processo. Tudo o que ele "ler" ou "escreve" terá sempre um sentido relacionado com seus sentimentos, suas experiências e pressupõe um interlocutor. Escreve para alguém e deseja que o outro saiba o que ele escreveu. 
Quanto mais a criança for estimulada a experimentar escrever e ler, quanto mais ela puder exercitar a leitura e a escrita livremente, sem pressões sem censura ou correções constantes, maior a possibilidade de desenvolver uma atitude positiva em relação a esse processo.

O trabalho com o código poderá ser desenvolvido simultaneamente à aplicação de jogos ou problemas a serem resolvidos e como informação contextualizada dispensando-se os exercícios mecânicos repetidos e isolados, como cópias, treinos de famílias silábicas e outros.

Além da convivência, da experimentação e da interação constantes a criança precisa também estar motivada a construir seu conhecimento sobre leitura e escrita. $\mathrm{O}$ processo precisa ser, portanto, ao mesmo tempo prazeroso e instigante.

\section{2 - O PAPEL DO PROFESSOR}

Para melhor compreender como se dá a construção do conhecimento da leitura e da escrita, o professor deve-se colocar-se no ponto de vista do aluno que aprende para saber verificar como e porque ele pensa e faz a sua escrita, procurando ainda compreender também o que é essencial e o que é periférico na leitura para decidir o que deve ser central e o que apenas complementar em seu trabalho pedagógico.

Para combinar a alfabetização e o letramento o professor precisa então, criar oportunidades em que a criança possa vivenciar intensamente atos de leitura e escrita. O ambiente escolar precisa ser um ambiente alfabetizador onde a criança será estimulada não só a desejar descobrir o significado de cada texto como ainda a produzir o seu próprio texto, segundo o autor:
Nas comunidades sociais, convivem culturas de letramento associadas a diferentes atividades: sociais, científicas, religiosa, profissionais etc. Também existem manifestações culturais letradas associadas à cultura popular. Uma cultura de letramento é constituída de práticas sociais em que as pessoas se apóiam em textos escritos e lidos ou lidos e preservados na memória (BORTONI, 2008, p.43).

Assim tão importante quanto ler histórias para os alunos é deixar que eles também leiam estas histórias quando além de imitar o ato do professor terão oportunidade de interagir com o texto e seus significados. Assim o professor deve estimular a criança, valorizando e acreditando que ela é capaz.

Essa expectativa por parte do professor é que possibilitará o surgimento de uma atitude positiva em relação à alfabetização e letramento. E a criança se perceberá capaz através de outros. Em uma prática construtiva torna-se de fundamental importância o princípio da confiança mútua da expectativa positiva de desempenho dessa criança na capacidade de aprender do aluno. O professor deve tratar o aluno como sujeito pensante, capaz, inteligente, ativo e logicamente também desejaste.

Nessa prática o professor não pensa, não faz e não fala pelo aluno, dar tempo, espaço e oportunidades para que ele próprio pense, faça e fale a respeito de suas idéias e experiências. Em cada resposta diferente o professor procura a positividade, os indícios de evolução e parte sempre para propor avanços e planejar novas atividades, pois ele sabe e acredita que seu aluno tem potencial para aprender sempre mais e melhorar seu desempenho. Moura (1999, p. 213) aponta que no processo de ensinoaprendizagem o educador deve partir dos 
interesses e realidade dos educados, tendo comprometimento na sua atuação, uma vez que:

Os motivos dos alfabetizados devem servir de motivação para os alfabetizadores. Devem despertarlhes o interesse e o desenvolvimento de atitudes no sentido de levar a sério a tarefa de alfabetizar, de pesquisar, de aprender, junto com eles, de entender a importância do planejamento e da organização da prática como extensão das exigências que são feitas nas práticas sociais mais amplas. (MOURA, 1999, p.213).

Podemos dizer que o núcleo do processo de alfabetização e letramento parece ter como fator decorrente essa relação positiva entre professor e aluno. Quando ela ocorre nesse nível todas as outras questões podem torna-se coadjuvantes e também positivas: metodologia, material, ambiente escolar, motivação, interesse e outras mais que se deseja considerar.

\section{3 - CONCLUSÃO}

Através dos estudos realizados letramento é um sistema aberto que permite ao ser humano ser criativo, construtor de textos, possibilitando a inovação no processo de ensino e aprendizagem, utilizando-se de recursos e experiências da vida cotidiana, a reinvenção de sua própria história e a compreensão de múltiplos significados, criando novas possibilidades para compreender e contextualizar o mundo.

Para dar conta dos objetivos iniciais foram utilizadas as bases teóricas de autores relacionados à alfabetização e letramento, pensando a alfabetização como um processo de construção indenitária, indo além do processo de decodificação de palavras e frases, mas como constituinte da sua aprendizagem e cidadania, nos campos políticos, sociais e culturais

Ser alfabetizado é compreender o que está escrito processar o significado da idéia que o autor pretende transmitir. Entra aí a perspectiva do letramento, fazendo com que o aluno exerça sua condição de alfabetizado sendo realmente um interlocutor do texto e compreendendo e questionando o conteúdo que lê.

Ao ler podemos interagir e desfrutar com criticidade do pensamento dos outros, enquanto que, ao escrever, podemos comunicar com autonomia e criatividade o próprio conhecimento, exercendo a habilidade do letramento e sua função social.

Para tanto, cada educador deve ter consciência e convicção de que não há um limite cognitivo, uma estabilidade, mas sucessivos progressos.

Deste jeito, é essencial que o professor utilize na sua prática, diferentes metodologias e variados textos que proporcionem tanto o desenvolvimento da alfabetização quanto o desenvolvimento do letramento de cada sujeito do qual ele possa ser autor de suas transformações.

Por tudo isso, é indispensável que se alfabetize letrando, ou seja, reconstruir a leitura e a escrita a partir do mundo vivenciado, criando um agradável vínculo através de práticas reais, contextualizadas e significativas. Acreditando que todos têm possibilidades de aprimoramento e dependemos uns dos outros para nos constituirmos em uma sociedade melhor.

\section{4 - REFERÊNCIAS}

BRASIL, Ministério da Educação e do Desporto. Parâmetros Curriculares 
Nacionais. Brasília: MEC/SEF, 1997.

BORTONI-RICARDO, S. M. Educação

em Língua Materna: a sociolinguística na

sala de aula. São Paulo: Parábola

Editorial, 2004.

CAGLIARI, Gladys; CAGLIARI, Luís

Carlos. Diante das letras: a escrita na

alfabetização. Campinas: Mercado das

letras; ALB, 1999.

MOURA, Tânia Maria de Melo. A prática

pedagógica dos alfabetizadores de

jovens e adultos: contribuições de freire,

ferreiro e vygotsky. Maceió:

EDUFAL/INEP 1999.

SOARES, Magda. Alfabetização e

letramento: um tema em três gêneros.

Belo Horizonte: Autêntica, 1998. 